\title{
Performing gas-exchange measurements on excised branches - evaluation and recommendations
}

\author{
J.E.C. MISSIK ${ }^{* * *}(\mathbb{D})$, A.C. OISHI ${ }^{* * *}$ (iD), M.C. BENSON*, V.J. MERETSKY*, R.P. PHILLIPS\# (D), \\ and K.A. NOVICK ${ }^{*++}$ \\ O’Neill School of Public and Environmental Affairs, Indiana University - Bloomington, $702 \mathrm{~N}$ Walnut Grove \\ Avenue, Bloomington, IN 47408, USA* \\ Department of Civil and Environmental Engineering, Washington State University, PO Box 642910, Washington \\ State University, Pullman, WA 99164, USA ${ }^{* *}$ \\ Coweeta Hydrologic Lab, USDA Forest Service - Southern Research Station, 3160 Coweeta Lab Road, Otto, \\ NC 28763, USA ** \\ Department of Biology, Indiana University-Bloomington, 1001 E. 3rd St., Bloomington, IN 47405, USA
}

\begin{abstract}
In forest canopies, it is common to perform leaf-level gas-exchange measurements on recently excised branches, often without testing for excision-related biases. We conducted a formal test of excision effects using gas-exchange measurements from cut and uncut canopy branches of three deciduous hardwoods - sugar maple (Acer saccharum Marsh.), tulip poplar (Liriodendron tulipifera L.), and white oak (Quercus alba L.). Across all species, excision immediately reduced photosynthesis and stomatal conductance by $27-62 \%$ relative to pre-excision rates. In white oak, which had particularly long $(>100 \mathrm{~cm})$ vessels, gas exchange was more impaired for shorter $(\sim 30 \mathrm{~cm})$ as compared to longer $(\sim 100 \mathrm{~cm})$ branches. Additional hypotheses linking branch height and species water-use strategy to excision bias were tested but not confirmed. A survey of 23 previously published studies confirms that our results are not without precedent. Excision-related biases should be considered when interpreting measurements performed on excised branches.
\end{abstract}

Keywords: canopy physiology; cut branch; hydraulics; isohydricity; measurement bias; methodology.

\section{Introduction}

Ecosystem carbon uptake and water loss through transpiration are regulated through leaf-level processes, including stomatal conductance $\left(g_{\mathrm{s}}\right)$ and the net rate of photosynthetic
$\mathrm{CO}_{2}$ assimilation $\left(P_{\mathrm{N}}\right)$. Over the past several decades, technological advances in portable leaf gas-exchange analyzers have enabled widespread, in situ measurements of these processes, spanning ecosystem types and local biophysical variability. These data are used to explore

\section{Highlights}

- Effects of branch excision on gas exchange were tested in three deciduous species

- Branch excision induced rapid declines in photosynthesis and stomatal conductance

- In a long-vesseled species, excision biases were greater in shorter branches
Received 14 August 2020

Accepted 19 November 2020

Published online 20 January 2021

Corresponding author

e-mail:knovick@indiana.edu

phone: 1-812-855-3010

Abbreviations: ABA - abscisic acid; $C_{\mathrm{i}}-$ intercellular $\mathrm{CO}_{2}$ concentration; $g_{\mathrm{m}}$ - mesophyll conductance; $g_{\mathrm{s}}$ - stomatal conductance; $P_{\mathrm{N}}$ - the net rate of photosynthetic $\mathrm{CO}_{2}$ assimilation; $\mathrm{T}_{\text {leaf }}$ - leaf temperature; $V_{\mathrm{cmax}}-$ maximum carboxylation rate; VPD - vapor pressure deficit; $\mathrm{WUE}_{\mathrm{i}}$ - intrinsic water-use efficiency.

Acknowledgments: The authors acknowledge Tyler Roman, Koong Yi, Chris Sobek, and Chelcy Miniat for help with data collection and operational support. We thank anonymous reviewers for comments that helped to improve this manuscript. This work was funded by the USDA Forest Service, Southern Research Station, and the Indiana University School of Public and Environmental Affairs. K. Novick acknowledges support from the National Science Foundation (NSF-DEB 1552747) and the USDA Agriculture and Food Research Initiative (AFRI, 2017-67013-26191).

Conflict of interest: The authors declare that they have no conflict of interest. 
how species-specific carbon uptake and water use respond to variable meteorological and stand conditions and are instrumental for testing new theories describing the mechanisms that determine these responses (Schuster and Monson 1990, Law et al. 2003, Long and Bernacchi 2003, Warren et al. 2015). These data are also often used for benchmarking and interpreting stand-scale carbon and water fluxes, such as those measured by eddy covariance (Schäfer et al. 2003, Roman et al. 2015) or represented in models (Dietze et al. 2011, LeBauer et al. 2013, Walker et al. 2014).

The introduction of commercially available portable photosynthesis systems in the 1980s and 1990s spurred an exponential increase in the number of papers reporting on the dynamics of leaf gas exchange (Long et al. 1996). By allowing $P_{\mathrm{N}}$, transpiration, and $g_{\mathrm{s}}$ to be observed outside of the lab, these systems facilitate investigations in remote study sites. They also support investigations of the impacts of environmental stress on native gas-exchange rates by permitting observations under conditions closely matched to those experienced by leaves growing in the field. In short-stature grasslands, shrublands, and croplands, it is relatively easy to access leaves in situ for observation. However, in taller, denser forest ecosystems, which are critical drivers of regional-to-global carbon cycling (Pan et al. 2011), accessing canopy leaves requires a canopy tower or crane, a boom lift, or professional tree climbers, which are logistically challenging to deploy. Consequently, gas exchange observations performed on branches that have been excised from the tree with the aid of a pole pruner, slingshot, or shotgun are widespread in the ecophysiological literature (Bernacchi et al. 2003, Santiago and Mulkey 2003, Koch et al. 2004, Ewers et al. 2007, Monson et al. 2007, Miyazawa et al. 2011). When using this approach, it is standard practice to immediately recut excised branches underwater after they are felled in order to refill the embolized xylem. In most cases, gasexchange measurements are performed within minutes after excision, though in some cases branches are returned to a laboratory setting and observed over a period of several hours to several days (Masarovičová and Štefančík 1990, Niinemets et al. 2005, Pou et al. 2013, and see supplement).

Despite the widespread use of the cut-branch approach, formalized tests for effects of excision on gas-exchange rates are rarely reported in the literature (e.g., Lange et al. 1986, Ginn et al. 1991, Santiago and Mulkey 2003, Miyazawa et al. 2011). Sometimes, authors report qualitatively on results from tests of excision effects, but do not show the data (Valladares et al. 1997, Warren et al. 2003, Ethier et al. 2006, Ewers et al. 2007, Joesting et al. 2009). In most cases, however, preliminary tests are not conducted, or at least the results of those tests are not reported (see the supplement for a representative listing of $\sim 30$ studies in this category). The excised branch approach relies strongly on the assumption that recutting branches underwater will minimize disruptions to the branch hydraulic system, including xylem embolism, which can rapidly alter leaf water status and gas-exchange variables (Salleo et al. 2000, Buckley 2005, Hanson et al.
2013, Sperry et al. 2016). However, formalized tests of this assumption are rarely included in experimental design.

Our study is motivated by a recognition that existing evidence provides an insufficient rationale for assuming that gas-exchange observations on excised branches can be performed on a wide range of tree species without bias. In fact, several studies report significant declines in either $P_{\mathrm{N}}$ or $g_{\mathrm{s}}$ from leaves on excised branches relative to intact branches (Lange et al. 1986, Santiago and Mulkey 2003). Moreover, some studies have found that stomata exhibit a 'wrong-way' response to excision, in which $g_{\mathrm{s}}$ increases immediately after excision while $P_{\mathrm{N}}$ declines (Buckley 2005, Hanson et al. 2013, Kwon and Choi 2014) - a process that can persist for up to $30 \mathrm{~min}$ post-excision. This may occur if $P_{\mathrm{N}}$ and $g_{\mathrm{s}}$ respond to different signals produced by disruptions in hydraulic transport, with $g_{\mathrm{s}}$ responding to a hydraulic signal and $P_{\mathrm{N}}$ responding to a wound-induced electrical signal (Hanson et al. 2013). Regardless of the mechanisms, there is little consensus in the literature as to which species may be most sensitive to measurement biases incurred by branch excision.

Different approaches to the regulation of $g_{\mathrm{s}}$ could determine species-specific responses to branch excision. Isohydric species, which include sugar maple and tulip poplar (Roman et al. 2015), close their stomata in response to relatively mild water stress, reducing their risk of cavitation but also limiting their photosynthetic capacity. In contrast, anisohydric species like white oak (Roman et al. 2015) operate under narrower hydraulic safety margins and maintain high $g_{\mathrm{s}}$ under conditions of water stress (Martínez-Vilalta et al. 2014). While the mechanisms responsible for species-specific regulation of $g_{\mathrm{s}}$ remain an active field of research, evidence suggests that there is at least some link between stomatal functioning over short time scales and hydraulic supply of water to the leaf (Buckley 2005, Sperry et al. 2016). Thus, it is reasonable to expect that species exhibiting remarkably divergent strategies for regulating $g_{\text {s }}$ may also be associated with contrasting responses of gas-exchange rates to branch excision, particularly if those species experiencing lower leaf water potentials are more prone to xylem cavitation. Relatedly, excision response could vary among upper and lower canopy branches due to a longer path length for upper canopy branches and since leaf water potential often decreases with height in order to compensate for gravitydriven declines in the water potential difference between leaves and the soil (Woodruff et al. 2004).

Additionally, response to excision could also vary with the length of excised branches. In species with particularly long xylem elements, like some vessel-bearing species, the length of the excised branches may not exceed the average xylem element length, ensuring that some excision-induced embolism will remain even after recutting branches underwater. Even if xylem elements are much shorter than the length of the excised branch, leaves on longer excised branches are likely to be separated by a greater distance from xylem embolized at the distal end of the branch and may be able to access water stored along the length of the branch, which could mitigate biases due to excision.

In this study, our goal is to critically assess the 
prevalence of excision-related biases in gas-exchange measurements, to explore their mechanistic basis, and to supply the community with practical recommendations for situations when performing gas-exchange measurements on excised branches cannot be avoided. Towards that end, using original observations, we quantify the magnitude of cut-branch biases in gas-exchange rates of three important eastern U.S. tree species: Acer saccharum Marsh. (sugar maple), Liriodendron tulipifera L. (tulip poplar), and Quercus alba L. (white oak), and use these data to test hypotheses related to xylem anatomy, water use strategy, and canopy position. The study species include one ringporous, anisohydric species (white oak) and two diffuseporous, isohydric species (sugar maple and tulip poplar). The specific hypotheses are:

Hypothesis $1(\mathrm{H} 1)$ : Response of $P_{\mathrm{N}}$ and $g_{\mathrm{s}}$ to branch excision will vary among species. We will test two competing hypotheses: H1a) Ring-porous species (white oak) will experience larger excision-induced reductions in $P_{\mathrm{N}}$ and $g_{\mathrm{s}}$ relative to the diffuse-porous species since the larger and longer vessels in the former are more vulnerable to embolism. H1b) Isohydric species (sugar maple and tulip poplar), which are known to more strongly regulate $g_{\text {s }}$ (Roman et al. 2015, Yi et al. 2017), will experience larger excision-induced reductions in $P_{\mathrm{N}}$ and $g_{\mathrm{s}}$ relative to the anisohydric white oak.

Hypothesis 2 (H2): Leaves on shorter excised branches will exhibit a greater decline in $P_{\mathrm{N}}$ and $g_{\mathrm{s}}$ than leaves on longer excised branches since leaves from longer branches are buffered from excision-related embolism by distance and by greater access to water stored within the stem.

Hypothesis 3 (H3): Leaves from upper canopy branches will exhibit a greater decline in $P_{\mathrm{N}}$ and $g_{\mathrm{s}}$ following excision than leaves on lower canopy branches, due to the decrease of leaf water potential with height.

We tested these hypotheses on multiple canopy trees (accessed by a boom lift) at the Morgan-Monroe State Forest (MMSF; south-central Indiana, USA). We complement the formal hypotheses testing with a thorough review of the existing literature on the effects of branch excision on gas-exchange rates for a broader range of boreal, temperate, and tropical tree species, in order to understand if our site-level results are representative of broader patterns.

\section{Materials and methods}

Study site: The MMSF is a managed deciduous broadleaf forest in south-central Indiana, USA $\left(39^{\circ} 19^{\prime} \mathrm{N}, 86^{\circ} 35^{\prime} \mathrm{W}\right.$, $275 \mathrm{~m}$ a.s.1.). The average age and height of the trees are 80-90 years and $27 \mathrm{~m}$, respectively. Since 1998, a 46-m Ameriflux tower has been operating continuously at MMSF, as described in detail elsewhere (Roman et al. 2015). Based on basal area, sugar maple is the dominant canopy species followed by tulip poplar, sassafras, and red and white oak, which together comprise nearly $75 \%$ of all basal areas in plots in the study area.

Gas-exchange measurements on intact and excised branches: Gas-exchange measurements $\left(P_{\mathrm{N}}\right.$ and $\left.g_{\mathrm{s}}\right)$ were performed between August-October of 2014 using an LI-6400 portable photosynthesis system fitted with a red/blue light source (Li-Cor Biogeosciences, Lincoln, $\mathrm{NE})$. All measurements were taken at $400 \mu \mathrm{mol}\left(\mathrm{CO}_{2}\right)$ $\mathrm{mol}^{-1}$ and PPFD of 1,500 $\mu \mathrm{mol} \mathrm{m} \mathrm{m}^{-2} \mathrm{~s}^{-1}$ and were recorded after checking for leaks and successfully matching the sample and reference gas analyzers. Relative humidity ranged from 33 to $64 \%$, and the instrument was set to control leaf temperature $\left(\mathrm{T}_{\text {leaf }}\right)$ at $25^{\circ} \mathrm{C}$ via control of the air temperature in the leaf chamber by the Peltier devices of the system (see below for a more thorough description of the temperature environment in the chamber). Measurements were completed before 13:00 h each day to avoid complications arising from high vapor pressure deficit (VPD) in the afternoon, which can induce stomatal closure. For purposes of this study, we defined an observation as the average of four gas-exchange measurements recorded at 45 -s intervals.

Gas-exchange measurements were made in sets on branches falling into one of three categories: (1) a control, attached branch; (2) a short ( $30 \mathrm{~cm})$ excised branch; and (3) a long $(\sim 100 \mathrm{~cm})$ excised branch. Canopy branches were accessed using a $25-\mathrm{m}$ boom lift. All measurements were performed in the boom lift close to where the branches were collected. For each set of measurements, several rounds of $P_{\mathrm{N}}$ and $g_{\mathrm{s}}$ observations were conducted. The first two measurement rounds occurred within an hour prior to abscission, noting that the pre-excision $P_{\mathrm{N}}$ fluctuated by less than $1 \mu \mathrm{mol} \mathrm{m} \mathrm{m}^{-2} \mathrm{~s}^{-1}$, on average, for each leaf (for a relative variation of $<10 \%$ ). Small but unavoidable errors in IRGA matching can translate to relatively large errors in the gas-exchange measurement if the fluxes are relatively small and the $\mathrm{CO}_{2}$ differential between the reference and sample cells is also small. In our experiment, an absolute difference of $1 \mu \mathrm{mol} \mathrm{m} \mathrm{m}^{-2} \mathrm{~s}^{-1}$ corresponded to a relative difference of $<10 \%$, which is not negligible but, as the results will show, is considerably less than variability in $P_{\mathrm{N}}$ linked to the branch treatments. Thereafter, the short and long branches were excised using a pruner and immediately recut while submerged in water in an attempt to refill xylem embolized during excision. The length of excised branches was determined as the distance from the measured leaves to the cut end of the branch. The cut branch ends remained submerged in water until all gasexchange measurements were completed. Three more rounds of measurements were performed between 5 and 110 min after excision. The $L I-6400$ 's sample and reference gas analyzers were matched approximately every $30 \mathrm{~min}$ during the measurement period.

There is some evidence that the mechanical stress induced by repeatedly clamping a leaf during measurements could reduce $g_{s}$ (Marler and Mickelbart 1992). We tested whether the process of repeatedly measuring the same leaf biases gas-exchange measurements by measuring gas exchange during each measurement round on both a repeated leaf (i.e., the same leaf was measured during each round) and a rotating set of leaves from the same branch (i.e., a previously unmeasured leaf was measured each round). This test was performed on all 13 sets of gas-exchange measurements and was performed on 
both attached and long excised branches. No significant difference between the repeating and rotating-leaf treatments was detected for either the attached or excised samples ( $p>0.40$ for all species). Thus, we used the set of repeated-leaf measurements to test the study hypotheses. Repeated-leaf measurements give more statistical power than rotating-leaf measurements to observe the effects of experimental treatments in this study, due to the natural leaf-to-leaf variability in gas-exchange rates of rotatingleaf measurements (data not shown).

The final dataset includes 13 sets of measurements, taken on nine different days, distributed among seven upper and six lower canopy sets. Upper canopy branches were located in the topmost portion of the canopy and received full sunlight. Lower canopy branches were located in the lower half of the canopy, which was almost fully shaded and received diffuse radiation for most of the day. It should be noted that because our experiment took place late in the growing season, it is likely that our trees were experiencing some degree of stress linked to the seasonal evolution of soil moisture deficits or the early phases of senescence. Nevertheless, the magnitude of $P_{\mathrm{N}}$ and $g_{\mathrm{s}}$ observed in this study is comparable to that observed for the same species in the same study-site during non-stressed conditions (Roman et al. 2015). Furthermore, because environmental stress should affect all treatment classes similarly, it should not complicate the analysis aimed at detecting excisionrelated biases.

\section{Correcting gas-exchange measurements for the effects} of $\mathbf{T}_{\text {leaf }}$ and VPD: For the majority of the measurement sets $(70 \%)$, the actual temperature of leaves from all branch types was within three degrees of the set point of $25^{\circ} \mathrm{C}$. However, a portion of the study period was characterized by relatively low ambient temperatures which challenged the instrument's ability to maintain the $25^{\circ} \mathrm{C}$ set point. As a result, four of the 13 measurement sets were conducted with $\mathrm{T}_{\text {leaf }}$ below $22^{\circ} \mathrm{C}$. Importantly, the chamber temperature was similar (i.e., within $1-2^{\circ} \mathrm{C}$ ) across all branch types during each measurement set; or in other words, reductions in chamber temperature affect control, short excised, and long excised branches similarly.

Nonetheless, because $P_{\mathrm{N}}$ is known to be dependent on $\mathrm{T}_{\text {leaf }}$ (Bernacchi et al. 2009), a temperature correction was applied to the $P_{\mathrm{N}}$ data in order to facilitate a comparison of trends across the measurement sets. Although the relationship between $P_{\mathrm{N}}$ and $\mathrm{T}_{\text {leaf }}$ is nonlinear, measurements of $\mathrm{T}_{\text {leaf }}$ in our dataset range from below-optimum temperatures to approximately optimum temperatures (i.e., $<26^{\circ} \mathrm{C}$ ), over which range the $P_{\mathrm{N}}-\mathrm{T}_{\text {leaf }}$ curve is monotonically increasing (Bernacchi et al. 2009). Thus, for this dataset, the effects of $\mathrm{T}_{\text {leaf }}$ on $P_{\mathrm{N}}$ may be approximated with a linear relationship. To correct for the effects of $\mathrm{T}_{\text {leaf }}$ on $P_{\mathrm{N}}$ in our analysis, we used linear mixed models for each species to determine the relationship between $P_{\mathrm{N}}$ and $\mathrm{T}_{\text {leaf }}$ for all measurements in our dataset taken on intact branches. Values of $P_{\mathrm{N}}$ were corrected to a $\mathrm{T}_{\text {leaf }}$ of $25^{\circ} \mathrm{C}$ according to the parameter estimates from these models. Additional details about these corrections are presented in the supplement.
Variations in chamber temperature and humidity also promoted variation in chamber VPD, which is a strong determinant of $g_{\mathrm{s}}$ (Leuning et al. 1995). To correct for VPD effects on $g_{s}$, we used linear mixed models for each species to determine the relationship between $g_{\mathrm{s}}$ and ln VPD for all measurements in our dataset taken on intact branches (see supplement for more details). Values of measured $g_{\mathrm{s}}$ were corrected to VPD $=1.5 \mathrm{kPa}$ according to the parameter estimates from these models. Additional details about the VPD correction are presented in the supplement. All subsequent statistical analyses and figures use $T_{\text {leaf }}$ - and VPD-corrected data.

Determining maximum vessel length: To help us interpret observations of the link between gas-exchange rates, excision, and branch length, maximum xylem vessel length was estimated using the air infiltration technique (Cochard et al. 2010). Upper canopy branch samples $100 \mathrm{~cm}$ in length were collected from two trees of each species $(n=5)$, the terminal bud was clipped and infiltrated with compressed $\mathrm{N}_{2}$ at $0.1 \mathrm{MPa}$. The basal end of the branch was submerged in water and 1-2-cm segments were removed with freshly sharpened hand pruners until bubbles were observed. At low xylem pressure (i.e., $0.1 \mathrm{MPa}$ ), compressed gas is confined to a single xylem vessel and cannot pass through vessel end walls. The presence of bubbles after cutting back branch tissue indicates end wall removal and an open vessel. Maximum xylem vessel length is determined as the subsequent remaining length of the branch sample.

Statistical analyses: All hypotheses were assessed using linear mixed models in SPSS Statistics. We ensured that model assumptions were not violated through visual assessment of the conditional raw residuals. We generated histograms and Q-Q plots of the conditional raw residuals and inspected these for any severe departures from normality. We generated scatter plots of the conditional raw residuals $v s$. predicted values and inspected these for evidence of nonconstant variance. Due to the small sample sizes in our dataset, formal tests of normality were not performed.

For each species, we tested whether branch excision had a significant effect on $P_{\mathrm{N}}$ and $g_{\mathrm{s}}$ using linear mixed models, including repeated measurements with a firstorder autoregressive structure. An indicator variable for measurements taken on excised branches was included as a fixed effect in the analyses, as well as canopy position and a canopy position $\times$ excision interaction term, and day of the year was included as a random effect in the analyses:

$$
P_{\mathrm{N}}=\beta_{0}+\beta_{1} \text { Excised }+\beta_{2} \text { Canopy }+\beta_{3} \text { Excised } \times \text { Canopy }+
$$$$
+\alpha_{\mathrm{DOY}}+\varepsilon
$$

$g_{\mathrm{s}}=\beta_{0}+\beta_{1}$ Excised $+\beta_{2}$ Canopy $+\beta_{3}$ Excised $\times$ Canopy +

$+\alpha_{\mathrm{DOY}}+\varepsilon$

where $\alpha_{\text {DOY }}$ represents the random effects of a day of the year and $\varepsilon$ represents the residual.

We used linear mixed models to analyze the effects of tree species, canopy position, and branch length on 
absolute and percent changes in $P_{\mathrm{N}}$ and $g_{\mathrm{s}}$ following excision. Leaf-specific changes in $P_{\mathrm{N}}$ and $g_{\mathrm{s}}$ following excision were calculated as the difference between the average of the two pre-excision values and the average of the three post-excision values. Tree species, canopy position, and a canopy position $\times$ tree species interaction term were included as fixed factors in the analyses, and day of year was included as a random factor in the analyses:

change in $P_{\mathrm{N}}=\beta_{0}+\beta_{1}$ Species $+\beta_{2}$ Canopy $+\beta_{3}$ Canopy $\times$ $\times$ Species $+\alpha_{\text {DOY }}+\varepsilon$

change in $g_{\mathrm{s}}=\beta_{0}+\beta_{1}$ Species $+\beta_{2}$ Canopy $+\beta_{3}$ Canopy $\times$ $\times$ Species $+\alpha_{\text {DOY }}+\varepsilon$

We performed pairwise comparisons among species to assess which species exhibited significant differences in their response to excision. To test whether branch length and canopy position had an effect on the magnitude of observed declines in gas-exchange rates following excision, we used linear mixed models for each species, including branch length, canopy position, and a canopy position $\times$ branch length interaction term as fixed factors in the analyses, and day of the year as a random factor in the analyses: change in $P_{\mathrm{N}}=\beta_{0}+\beta_{1}$ Branch length $+\beta_{2}$ Canopy +

$+\beta_{3}$ Canopy $\times$ Branch length $+\alpha_{\text {DOY }}+\varepsilon$

change in $g_{\mathrm{s}}=\beta_{0}+\beta_{1}$ Branch length $+\beta_{2}$ Canopy +

$+\beta_{3}$ Canopy $\times$ Branch length $+\alpha_{\text {DOY }}+\varepsilon$

\section{Results}

General and species-specific effects of branch excision on gas-exchange rates (H1): Branch excision reduced $P_{\mathrm{N}}$ and $g_{\mathrm{s}}$ for all three species $\left(P_{\mathrm{N}}: p<0.0005 ; g_{\mathrm{s}}: p<0.010\right.$; Fig. 1, Table 1). Reductions in $P_{\mathrm{N}}$ were on the order of $30-60 \%$, and reductions in $g_{\mathrm{s}}$ were on the order of $30-40 \%$. In most cases, the declines in $P_{\mathrm{N}}$ and $g_{\mathrm{s}}$ were evident in observations collected during the first postexcision round of measurements (typically 5-20 min after cutting; Fig. 1) and persisted for over an hour postexcision. Furthermore, the leaves of almost all excised branches were associated with gas-exchange rates that fell below the pre-excision values (Fig. 1), and thus results were not driven by a few anomalous branches.

Individual species exhibited significant differences in the magnitude of their responses to excision. $P_{\mathrm{N}}$ of white oaks experienced greater absolute and relative declines

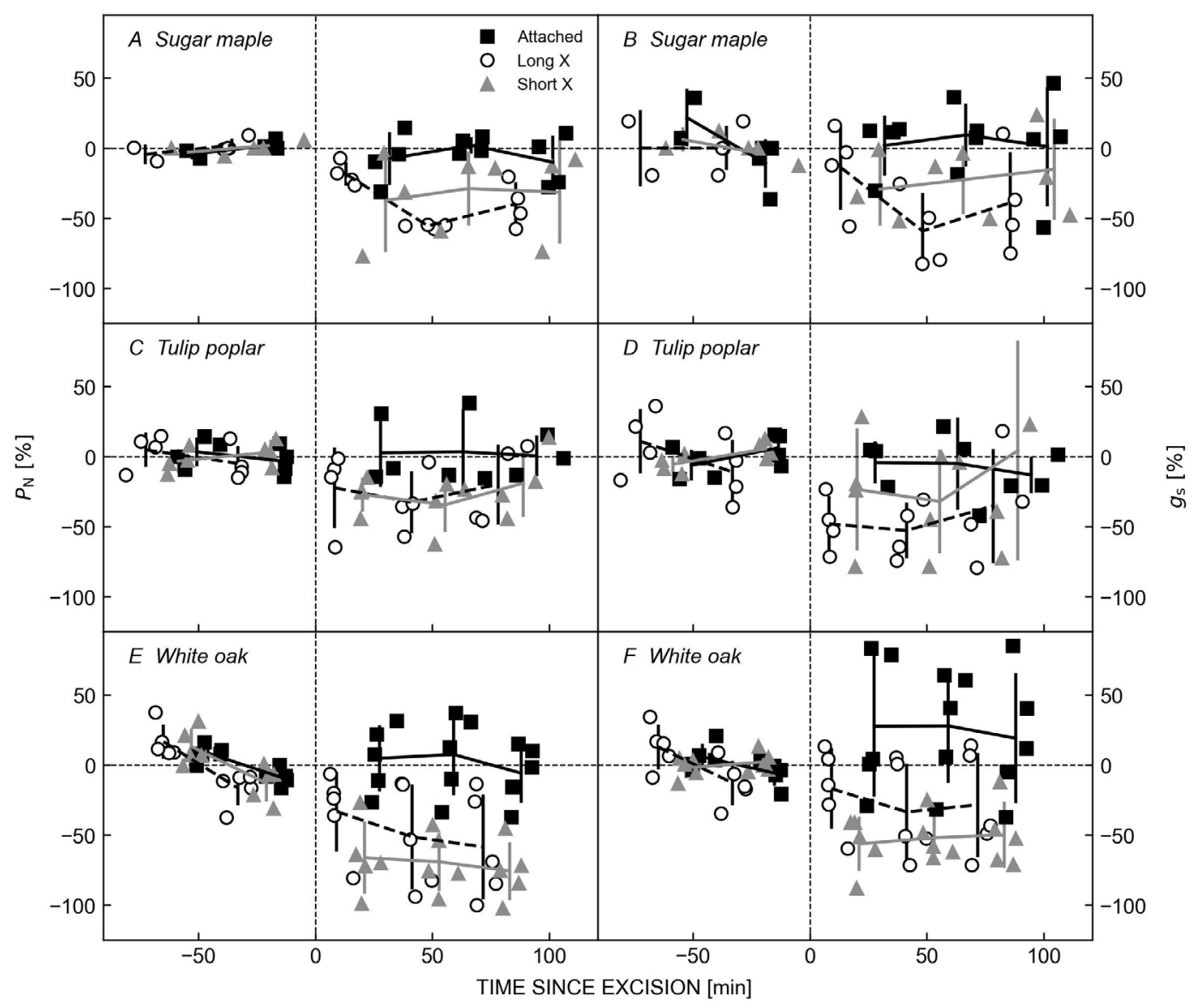

Fig. 1. The relative change in net photosynthetic rate $\left(P_{\mathrm{N}}\right.$, left column $)$ and stomatal conductance $\left(g_{\mathrm{s}}\right.$, right column $)$ as a function of time since excision. Black squares represent attached, never cut branches, open circles represent long excised branches, and gray triangles represent short excised branches. Data are from multiple branches experiencing each treatment. Error bars represent means \pm SD $(n=2-5)$. 
Table 1. Results of the literature survey of relative changes in net photosynthesis $\left(P_{\mathrm{N}}\right)$ and stomatal conductance $\left(g_{\mathrm{s}}\right)$ following branch excision and recutting under water. The observations reported here represent changes within the first 30 min of excision. Results from the present study (means $\pm \mathrm{SE}$ ) are also included for reference. ${ }^{1}$ The authors report gas-exchange rates remained high for excised branches preconditioned in dim light for $2-3 \mathrm{~d}$.

\begin{tabular}{|c|c|c|c|c|c|}
\hline Species & Location & Xylem anatomy & Relative change in $P_{\mathrm{N}}$ & Relative change in $g_{\mathrm{s}}$ & Reference \\
\hline \multicolumn{6}{|l|}{ (A) Data shown } \\
\hline Quercus alba & Indiana, USA & ring-porous & $-62.7 \%(5.8)$ & $-42.7 \%(7.9)$ & this study \\
\hline Liriodendron tulipifera & Indiana, USA & diffuse-porous & $-26.7 \%(6.3)$ & $-31.2 \%(8.6)$ & this study \\
\hline Acer saccharum & Indiana, USA & diffuse-porous & $-35.2 \%(6.8)$ & $-31.5 \%(9.3)$ & this study \\
\hline Lithocarpus edulis & Fukouka, Japan & semi-ring-porous & ns & $+55 \%(33)$ & Miyazawa et al. 2011 \\
\hline Pinus taeda & Virginia, USA & nonporous & ns & & Ginn et al. 1991 \\
\hline Picea abies & $\begin{array}{l}\text { Fichtelgebirg, } \\
\text { Germany }\end{array}$ & nonporous & $>-10 \%$ & -10 to $-30 \%$ & Lange et al. 1986 \\
\hline Picea rubens & $\begin{array}{l}\text { New Brunswick, } \\
\text { Canada }\end{array}$ & nonporous & $>-90 \%$ & $>-50 \%$ & Meng and Arp 1992 \\
\hline Jacaranda copaia & Panama & diffuse-porous & $-9 \%$ & similar to change in $P_{\mathrm{N}}$ & Santiago and Mulkey 2003 \\
\hline Apeiba membranacea & Panama & semi-ring-porous & $-22 \%$ & similar to change in $P_{\mathrm{N}}$ & Santiago and Mulkey 2003 \\
\hline Aspidosperma cruenta & Panama & diffuse-porous & $-25 \%$ & similar to change in $P_{\mathrm{N}}$ & Santiago and Mulkey 2003 \\
\hline Brosimum utile & Panama & diffuse-porous & $-70 \%$ & similar to change in $P_{\mathrm{N}}$ & Santiago and Mulkey 2003 \\
\hline Manilkara bidentata & Panama & diffuse-porous & $-39 \%$ & similar to change in $P_{\mathrm{N}}$ & Santiago and Mulkey 2003 \\
\hline Simarouba amara & Panama & diffuse-porous & $-33 \%$ & similar to change in $P_{\mathrm{N}}$ & Santiago and Mulkey 2003 \\
\hline Anacardium excelsum & Panama & diffuse-porous & $-57 \%$ & similar to change in $P_{\mathrm{N}}$ & Santiago and Mulkey 2003 \\
\hline Luehea seemannii & Panama & diffuse-porous & $-15 \%$ & similar to change in $P_{\mathrm{N}}$ & Santiago and Mulkey 2003 \\
\hline $\begin{array}{l}\text { Pseudobombas } \\
\text { septenatum }\end{array}$ & Panama & & $-60 \%$ & similar to change in $P_{\mathrm{N}}$ & Santiago and Mulkey 2003 \\
\hline
\end{tabular}

(B) Data not shown

Many

Bukina Faso, Mali, and Ghana

Many Far North Queensland, Australia

Many

Manitoba, Canada nonporous and

Three subalpine conifers Colorado, USA

Castanea mollissima Ohio, USA

Acer saccharum

Many

Vermont, USA

Barro Colorado Island, Panama

Pseudotsuga menziesii British Columbia, Canada

Pseudotsuga menziesii

British Columbia, Canada

Quecus ilex

Trention, Italy

North Carolina, USA nonporous

Pinus taeda

Japan

Pinus densiflora

Victoria, Australia

Tuscany, Italy

Populus spp.

Pseudotsuga menziesii

Vancouver Island, BC, Canada

Liquidambar styraciflua Tennessee, USA

Populus spp.

Viterbo, Italy

very low $g_{\mathrm{s}}$ observed for $20 \%$ of excised

Domingues et al. 2010 branches

11 of 125 observation rejected for very low $g_{\mathrm{s}}$ Bloomfield et al. 2014 diffuse-porous nonporous and diffuse-porous nonporous ring-porous

gas exchange not affected by excision

gas exchange not affected by excision

gas exchange not affected by excision

leaves viable for gas exchange within $5 \mathrm{~min}$ of excision

diffuse-porous gas exchange not affected by excision diffuse-porous

nonporous

nonporous

diffuse-porous

nonporous

nonporous

diffuse-porous

nonporous

diffuse-porous

diffuse-porous gas exchange not affected by excision

gas exchange not affected by excision

gas exchange not affected by excision

$g_{\mathrm{s}}$ dropped rapidly in leaves that were not preconditioned $^{1}$

leaves viable for gas exchange within $15 \mathrm{~min}$ of excision

gas exchange not affected by excision

gas exchange not affected by excision

gas exchange not affected by excision

gas exchange not affected by excision

leaves viable for gas exchange within $2 \mathrm{~h}$

of excision

gas exchange not affected by excision
Dang et al. 1997

Lichtenthaler et al. 2007

Huxman et al. 2003

Joesting et al. 2009

Ellsworth and Liu 1994

Valladares et al. 1997

Ethier et al. 2006

Zhang et al. 1993

Niinemets et al. 2005

Ewers et al. 2007

Han 2011

Warren 2006

Urban et al. 2008

Warren et al. 2003

Monson et al. 2007

Bernacchi et al. 2003 
following excision than $P_{\mathrm{N}}$ of sugar maple and tulip poplar (Fig. 2). Absolute and relative declines in $P_{\mathrm{N}}$ following excision were similar for sugar maple and tulip poplar.

Absolute declines in $g_{\mathrm{s}}$ following excision also varied significantly among the three species tested (Fig. 3A,C,E). $g_{\mathrm{s}}$ for tulip poplar experienced significantly greater absolute decline following excision than $g_{\mathrm{s}}$ of sugar maple or white oak (Fig. 3). The absolute decline in $g_{\mathrm{s}}$ following excision was similar for sugar maple and white oak. Relative declines in $g_{\mathrm{s}}$ following excision did not vary significantly among the three species tested (Fig. $3 B, D, F$ ).

The different sensitivity of $P_{\mathrm{N}}$ and $g_{\mathrm{s}}$ to an excision in white oak caused a significant decrease in the intrinsic water-use efficiency $\left(\mathrm{WUE}_{\mathrm{i}}=P_{\mathrm{N}} / g_{\mathrm{s}}\right.$; Beer et al. 2009) among excised branches for white oak (Fig. 4). The WUE did not change significantly after excision for the other two study species. The differences in $\mathrm{WUE}_{\mathrm{i}}$ pre- and postexcision are similar to the dynamics of intercellular $\mathrm{CO}_{2}$ concentration $\left(C_{\mathrm{i}}\right)$ but opposite in direction (compare Fig. 4 to Fig. $3 \mathrm{~S}$ in the supplement).

Effects of branch length on response to excision (H2), and maximum vessel length: For white oak, short branches were associated with greater relative declines in $P_{\mathrm{N}}$ (Fig. $2 F$ ) and $g_{\mathrm{s}}$ (Fig. $3 F$ ) following excision than long branches. In the case of sugar maple and tulip poplar, branch length had no discernible effect on absolute or relative decline in $P_{\mathrm{N}}$ or $g_{\mathrm{s}}$ following excision (Figs. $2 A-D$, $3 A-D)$.

Sugar maple and tulip poplar were associated with relatively small xylem vessels that were much shorter than the minimum excised branch length. We determined the mean maximum vessel length of sugar maple to be $11.9 \mathrm{~cm}$ $(\mathrm{SD}=3.1 \mathrm{~cm})$, and the mean maximum vessel length of tulip poplar to be $9.4 \mathrm{~cm}(\mathrm{SD}=3.0 \mathrm{~cm})$. In contrast, the mean maximum vessel length of oaks exceeded $100 \mathrm{~cm}$ (i.e., the length of the longest excised branches) for all samples assessed for maximum branch length (Fig. 5).

Effects of canopy position on a response to excision (H3): We observed mixed results for the effects of canopy position on excision response (Fig. 6). For white oak, upper canopy branches exhibited significantly greater absolute and percent declines in $P_{\mathrm{N}}$ and $g_{\mathrm{s}}$ following excision than lower canopy branches. For tulip poplar, lower canopy branches exhibited a significantly greater

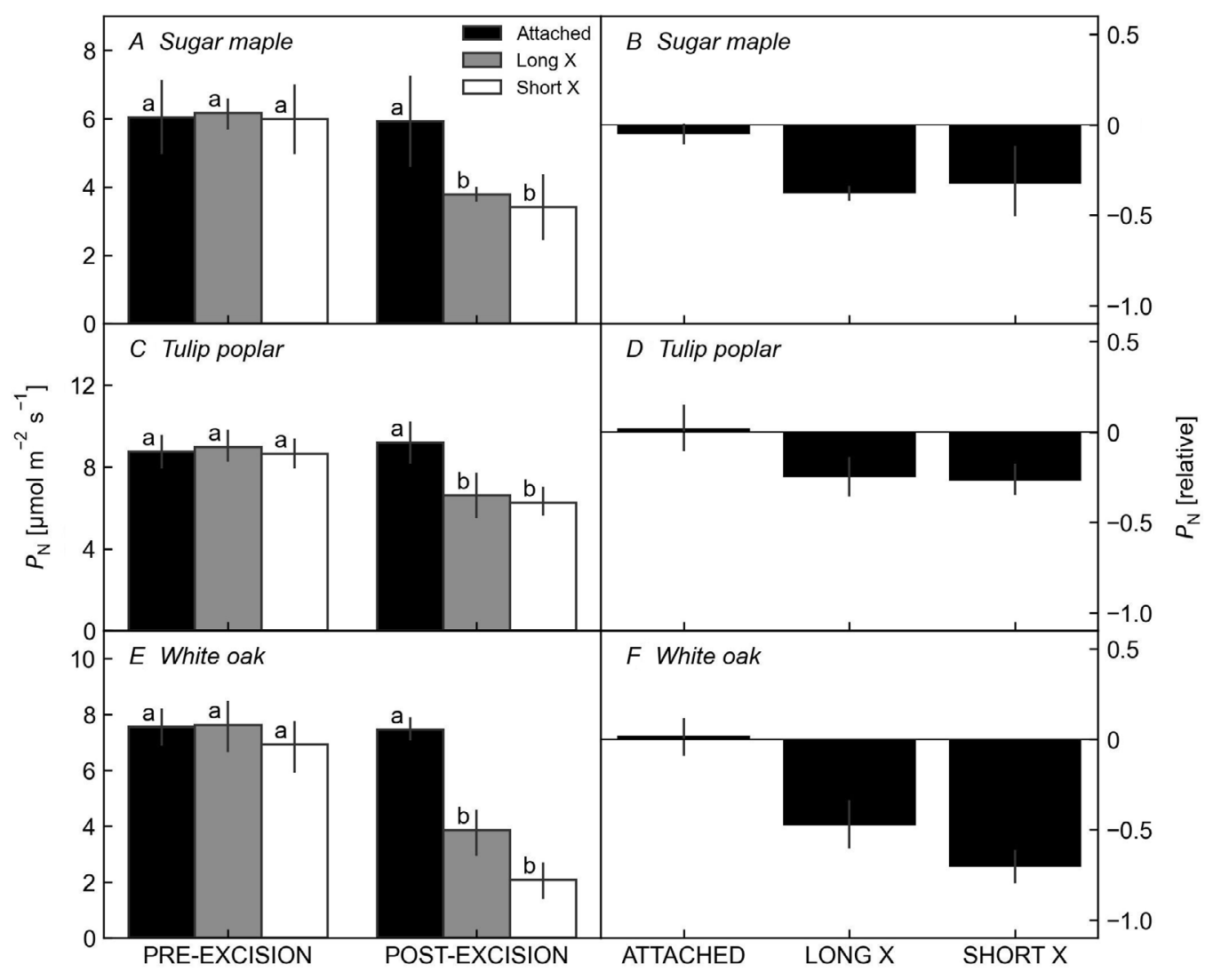

Fig. 2. The absolute (left column) and relative (right column) change in the net photosynthetic rate $\left(P_{\mathrm{N}}\right)$ as a function of branch treatment and species. 'Short X' means short excised branch and 'Long X' means long excised branch. Error bars represent means $\pm \mathrm{SE}(n=3-5)$. For all species, excision significantly reduced $P_{\mathrm{N}}$ by a confidence level of at least $p=0.05$, regardless of branch length. The letters in panels $(A),(C)$, and $(E)$ indicate differences in the mean between data groups, where groups with unique letters differ from one another at a confidence level of at least $p<0.05$. In the case of white oak, the $P_{\mathrm{N}}$ of short excised branches tended to be lower than that of long excised branches, but only at a confidence level of $p=0.078$. 


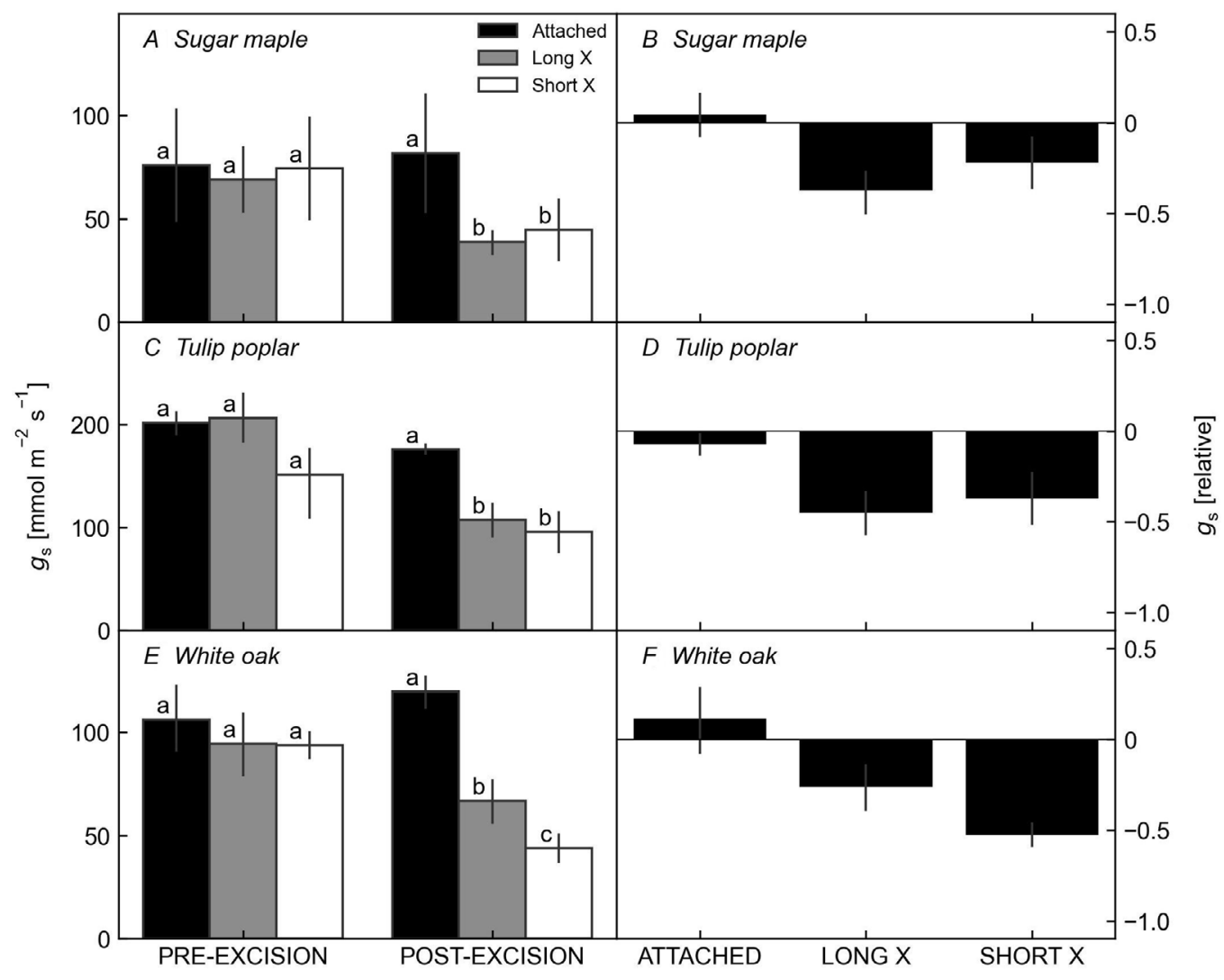

Fig. 3. The absolute (left column) and relative (right column) change in the stomatal conductance $\left(g_{\mathrm{s}}\right)$ as a function of branch treatment and species. 'Short X' means short excised branch and 'Long X' means long excised branch. Error bars represent means $\pm \operatorname{SE}(n=3-5)$. For all species, excision significantly reduced $P_{\mathrm{N}}$ by a confidence level of at least $p=0.05$, regardless of branch length. The letters in panels $(A),(C)$, and $(E)$ indicate differences in the mean between data groups, where groups with unique letters differ from one another at a confidence level of at least $p<0.05$.

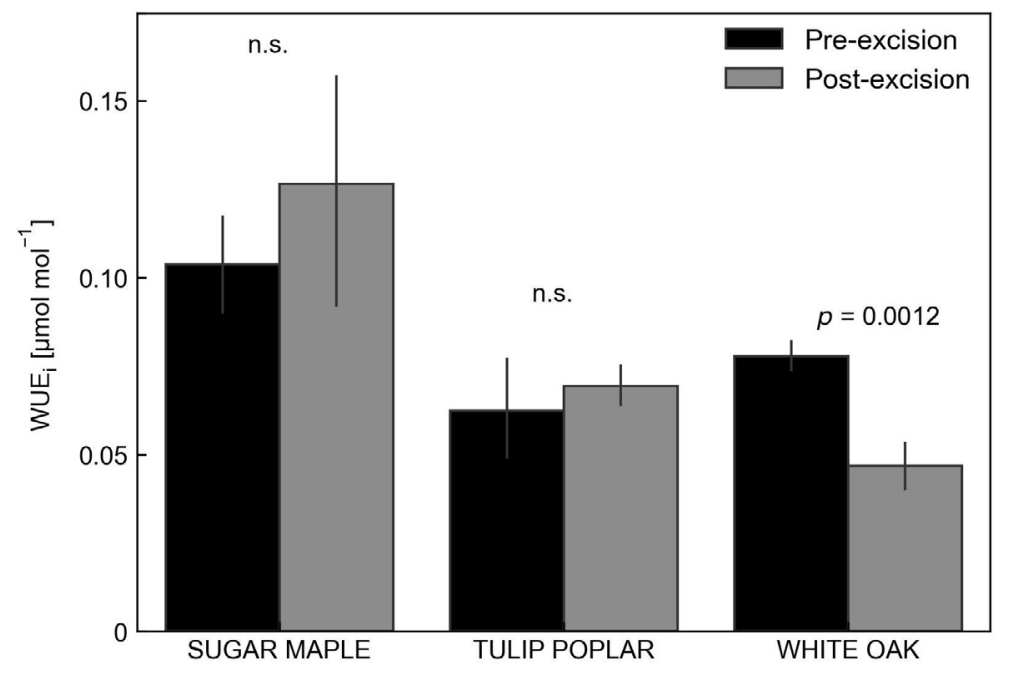

Fig. 4. The absolute intrinsic water-use efficiency $\left(\mathrm{WUE}_{\mathrm{i}}\right.$ ) before (black bars) and after (gray bars) excision for the study species. Long and short excised branches have been averaged together here. Error bars represent means $\pm \mathrm{SE}(n=$ 7-10). The $p$-value is shown for the difference between pre- and post-excision $\mathrm{WUE}_{\mathrm{i}}$ of white oak; differences were not significant for the other species. percent decline in $P_{\mathrm{N}}$ and $g_{\mathrm{s}}$ following excision than upper canopy branches. For sugar maple, canopy position had no significant effect on absolute or percent decline in $P_{\mathrm{N}}$ or $g_{\mathrm{s}}$ following excision.

\section{Discussion}

Bias associated with excised branch measurements: Performing gas-exchange measurements on excised bran- 


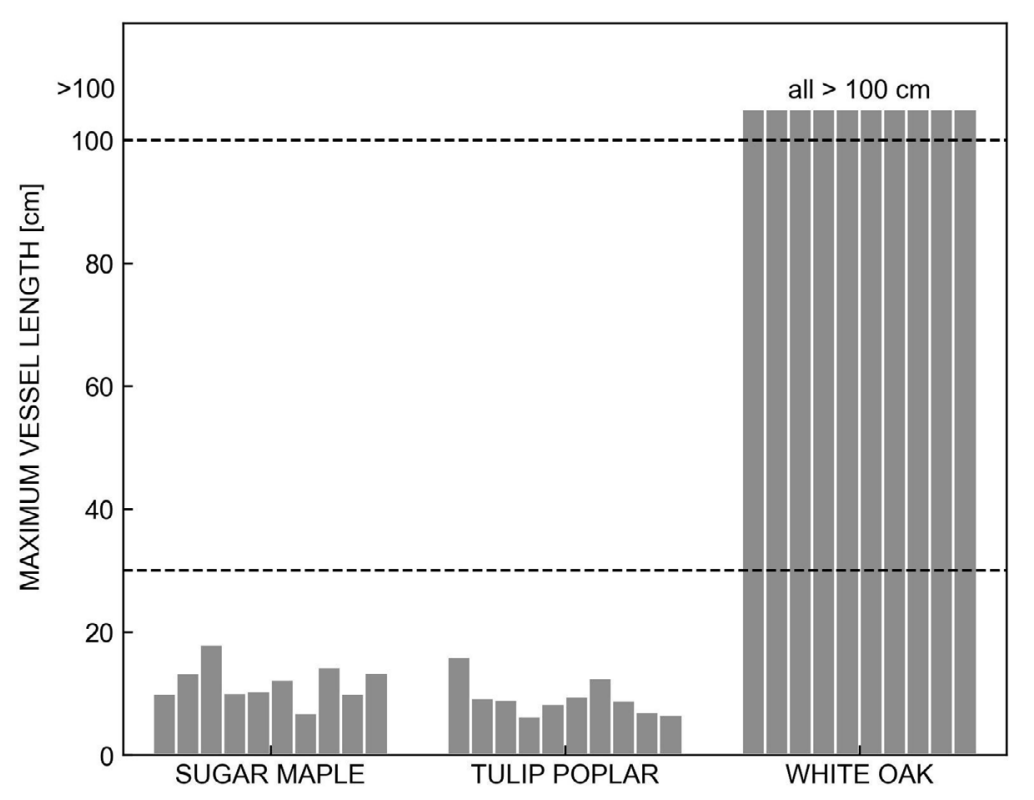

Fig. 5. The maximum vessel length estimated for ten branches of each species. In the case of white oak, the vessel length was determined to be longer than the branch length $(100 \mathrm{~cm})$ for all samples. Dashed lines represent the two sample lengths used in the experiment $(30$ and $100 \mathrm{~cm})$.

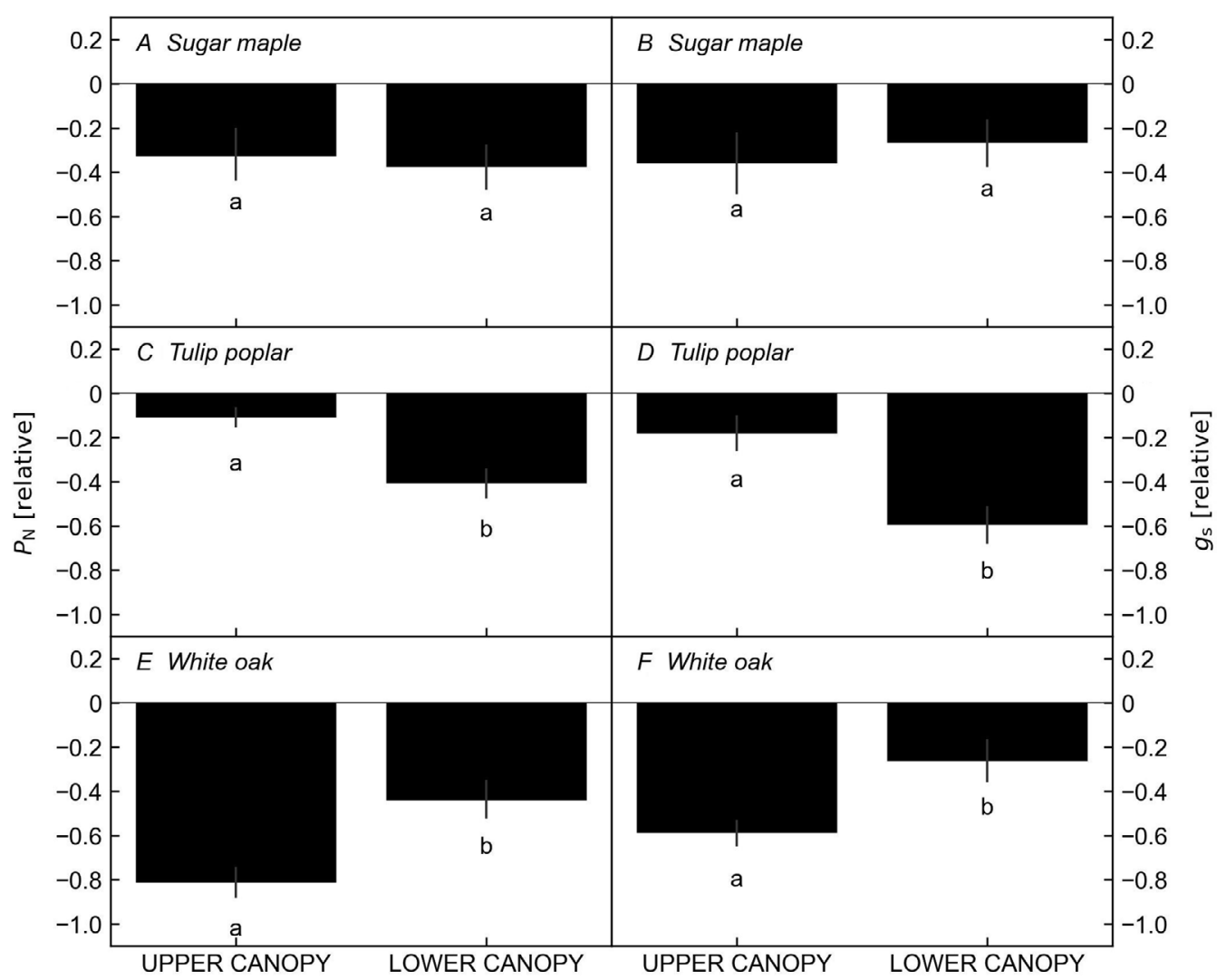

Fig. 6. The relative change in $P_{\mathrm{N}}$ (left column) and $g_{\mathrm{s}}$ (right column) after excision for upper and lower canopy leaves of each species. In this figure, data from short and long excised branches have been averaged together. Error bars represent means \pm SE $(n=3-6)$. The letters indicate differences in the mean between upper and lower canopy branches, where groups with unique letters differ from one another at a confidence level of at least $p<0.05$.

ches as a substitute for in situ branches is a widespread practice. These data are used to test ecological hypotheses at the site level, to upscale species-specific functioning to stand-level variables, and to inform the parameterization of terrestrial ecosystem models. However, our results suggest this approach can introduce significant bias. 
Among all three of our study species, branch excision rapidly decreased $P_{\mathrm{N}}$ and $g_{\mathrm{s}}$ by $25-60 \%$ of the pre-excision values (Figs. 1, 2, 3; Table 1), and these reductions in gas exchange were sustained for up to $100 \mathrm{~min}$ post-excision.

An exhaustive literature search of studies previously reporting excision effects on gas-exchange rates reveals that our results are not without precedent (see Table 1). Ten previously published studies, considering a wide range of species, reported some effect of branch excision on $P_{\mathrm{N}}$ and/or $g_{\mathrm{s}}$ (Table 1), with large (i.e., 10-30\%) and immediate declines in gas-exchange variables after excision reported in several cases (Lange et al. 1986, Meng and Arp 1992, Santiago and Mulkey 2003). Three of these studies reported that gas-exchange rates remained stable only for a relatively short period of time post excision; for example, five minutes in the case of a deciduous temperate species (Castanea mollissima; Joesting et al. 2009), 15 min in the case of a temperate evergreen species (Pinus taeda L.; Ewers et al. 2007), and $120 \mathrm{~min}$ in the case of another deciduous temperate species (Liquidambar styraciflua; Monson et al. 2007). Two studies simply reported that a fraction of observations (i.e., 10-20\%) had to be discarded due to very low values of $g_{\mathrm{s}}$ associated with excised branches (Domingues et al. 2010, Bloomfield et al. 2014). And finally, one study reported that $g_{s}$ dropped rapidly in excised branches measured in the field, but that $g_{\mathrm{s}}$ rates remained high for branches that were first preconditioned in the laboratory at low light for a period of 2-3 d, and then exposed to environmental conditions characteristic of the in situ environment (Niinemets et al. 2005).

Of the studies in Table 1, 13 reported that branch excision did not affect gas-exchange rates. However, for 12 of these 13 studies, data were not shown and results were described only qualitatively (i.e., category $(B)$ in Table 1). Thus, in many of these cases, it is not known how many branches were tested and for how long, and whether the results were statistically significant. As described in the supplement, dozens of additional studies rely on excised-branch gas-exchange measurements without any discussion of the potential for bias due to excision. It should also be noted that 7 of the 13 studies reporting that branch excision did not affect gas-exchange rates only examined conifers, whose less vulnerable xylem (Hacke and Sperry 2001) could potentially help mitigate the effects of excision effects.

Mechanistic basis of excision response: Our experimental design permitted us to test three mechanistic hypotheses regarding the links between excision-related reductions in gas exchange and xylem anatomy, water-use strategy, and canopy position. Results permit some insight into the processes responsible for the declines in gas-exchange variables after excision. In the case of the long-vessel white oak, longer branches reduced excision effects (Figs. $2 F, 3 F$ ), in support of the hypothesis that biases would be greater for shorter excised branches. This prediction was not confirmed in the case of the other two species, which notably were found to have short $(<12 \mathrm{~cm})$ vessels. In the case of short excised branches, relative reductions in both $P_{\mathrm{N}}$ and $g_{\mathrm{s}}$ were greater for white oak than sugar maple and tulip poplar (Table 1; Figs. 2, 3). This result supports Hypothesis $1 \mathrm{a}$, which predicted that white oak would be more sensitive to excision biases due to their long and wide vessels. The maximum xylem vessel length data also lend support to this hypothesis. Specifically, observations suggest that the maximum xylem vessel length of oaks $(>100 \mathrm{~cm})$ exceeds the length of the excised branches used in this study. Thus, it is reasonable to assume some degree of embolism was present for even the long (i.e., $100 \mathrm{~cm}$ ) excised oak branches, and may have been greatest for the relatively short (i.e., $30 \mathrm{~cm}$ ) oak samples. Unfortunately, excising branches longer than $100 \mathrm{~cm}$ would be logistically difficult and could pose a safety risk. In contrast, the maximum vessel lengths of sugar maple and tulip poplar were $11.9 \mathrm{~cm}$ and $9.4 \mathrm{~cm}$, respectively. These vessels are much shorter than the 30 and $100 \mathrm{~cm}$ branch samples used in this study. Furthermore, a length of $\sim 10 \mathrm{~cm}$ is comparable to the length of the branch ends that were removed from the gas-exchange samples when they were recut under water. Therefore, we conclude that, for sugar maple and tulip poplar, extensive xylem embolism cannot explain the reductions in gas exchange after excision. The results from previous studies also provide some evidence that xylem anatomy could influence the magnitude of excision effects. The short tracheids of coniferous species could help explain the lack of excision bias reported by many of the studies in Table 1 . However, the lack of consistent methods (i.e., length of excised branches and whether branches were recut under water) prevents a detailed analysis of the relationships between xylem anatomy, excision-induced embolism, and the magnitude of excision bias across studies. We also note that none of the other studies in Table $1 A$ examined ringporous species, which supports the need for additional testing of excision effects in other ring-porous species.

We found that the water-use strategy was not a strong determinant of the magnitude of post-excision reductions in gas exchange. When considering data from long branches only, gas-exchange rates for all species were reduced by similar relative magnitudes: $37 \%$ for sugar maple, $25-45 \%$ for tulip poplar, and 36-48\% for white oak (compared to declines of $50-70 \%$ for short, excised branches of white oak). Previous work from the site has demonstrated that tulip poplar is an exceptionally isohydric species, closing its stomata quickly in response to hydrologic stress (Roman et al. 2015, Yi et al. 2017). On the other hand, oak species maintain or even increase $g_{\mathrm{s}}$ during periods of hydrologic stress for a given VPD (Roman et al. 2015). Thus, speciesspecific strategies for regulating $g_{\mathrm{s}}$ do not appear to explain post-excision biases.

We also considered canopy position and height-related patterns in midday leaf water potential as possible drivers of post-excision reductions in gas-exchange variables. In the case of white oak, gas-exchange variables were more strongly reduced among upper as compared to lower canopy branches (Fig. 6). Previously reported observations from the site indicate that midday leaf water potential is lower in the upper as compared to lower canopy branches of white oak, but not the other more isohydric species (Roman et al. 2015). Thus, greater cavitation vulnerability 
among upper canopy branches may explain the heightrelated trends in post-excision gas-exchange dynamics for white oak, in partial support of Hypothesis 3. The similarity in leaf water potential between upper and lower canopy branches of sugar maple is also consistent with the similar response of gas-exchange variables observed for upper and lower canopy branches of this species (Fig. 6). However, the similarity in leaf water potential between upper and lower canopy branches of tulip poplar cannot explain the observed trend of larger reductions in gasexchange variables among lower canopy leaves of this species (Fig. 6). Sample sizes are somewhat limited when we separate upper and lower canopy data, which may contribute to the absence of a consistent effect of canopy position across species. Considering the previous studies reporting that gradients in leaf water potential with height can vary among different species in a site (e.g., Aranda et al. 2000) and that the different sensitivities of upper and lower canopy leaves to water stress can vary by species (Cano et al. 2013), future studies should consider that the effects of canopy position on excision bias may not be consistent across species. Besides, the responses of $g_{\mathrm{s}}$ and mesophyll conductance $\left(g_{\mathrm{m}}\right)$ to changes in light conditions can differ between sun and shade leaves (Campany et al. 2016), which could potentially influence the magnitude of excision bias at different canopy positions.

In summary, strictly hydraulic factors, including the extent of embolized xylem and patterns in in situ leaf water potential, offer a partial explanation of the observed gas-exchange dynamics of excised oak branches but do not explain post-excision reductions in $P_{\mathrm{N}}$ and $g_{\mathrm{s}}$ of the other study species. The proximate cause of the relatively similar reductions in gas-exchange variables for long branches of all species could still be hydraulic in origin if cutting rapidly produces a chemical or hormonal signal that is often hypothesized to drive stomatal closure (Buckley 2005, McAdam and Brodribb 2015). For example, there is evidence that the phytohormone abscisic acid (ABA) plays a role in regulating $g_{\mathrm{s}}$ in response to changes in leaf water status (Buckley 2005, Brodribb et al. 2017) but additional work is needed to determine the effects of branch excision on this process. However, in our study, we detected no evidence of the transient 'wrong-way' response of $g_{\mathrm{s}}$ to leaf excision that is consistently reported in response to leaf excision (without recutting under water) and other disruptions to the hydraulic pathway (Buckley 2005). It should be noted that most studies of the wrong-way response focus on the excision of a single leaf or leaflet, and not excision several tens of centimeters downstream along the branch. In any event, for the observations presented here, whatever signaling mechanism may be responsible for the so-called 'wrong-way' response would appear to be disrupted by recutting, or else was never activated in the first place.

We also note a need for further research to determine whether the mechanism responsible for the excisionrelated biases is primarily linked to stomatal functioning, or also affects nonstomatal factors such as $g_{\mathrm{m}}$ and biochemical capacity (e.g., the maximum carboxylation rate, or $\left.V_{\text {cmax }}\right)$. A number of studies have demonstrated that water stress can induce rapid changes in $g_{\mathrm{m}}$ (see Flexas et al. 2008 for a review), which suggests that branch excision could also affect $g_{\mathrm{m}}$. The relationship between $g_{\mathrm{s}}$ and $C_{\mathrm{i}}$ is relatively linear, but the relationship between $P_{\mathrm{N}}$ and $C_{\mathrm{i}}$ is hyperbolic. Thus, in the absence of limitations to photosynthetic capacity, a decline in $g_{\mathrm{s}}$ should be associated with a relatively smaller decline in $P_{\mathrm{N}}$ and an increase in $\mathrm{WUE}_{\mathrm{i}}$. Such a response was not observed in our data; the $\mathrm{WUE}_{\mathrm{i}}$ of sugar maple and tulip poplar was not affected by excision, and the $\mathrm{WUE}_{\mathrm{i}}$ of oaks declined after excision (Fig. 4). Thus, mechanisms affecting both stomatal and nonstomatal factors may be triggered by branch excision, and a future test of excision effects on the shape of $P_{\mathrm{N}}-C_{\mathrm{i}}$ curves would be illuminating.

Recommendations: Our findings, including both the generation of original data and the synthesis of previously published literature, illustrate that the use of excised branches for gas-exchange measurements can be associated with significant bias in the results and that in situ observations on attached branches should be attempted whenever possible. When site conditions leave researchers with no other option but to perform measurements on excised branches, we recommend cutting branches to lengths that are much longer than the average speciesspecific vessel length and recognizing that even then data from excised branches may underestimate the true rates of $P_{\mathrm{N}}$ and $g_{\mathrm{s}}$. Moreover, given that the magnitude of the excision bias varies among species, inter-species comparisons that rely on data from excised branches may be unreliable. For new studies, we recommend species-specific testing on branches that are accessible for in situ measurements, which may yield excised branch correction factors. This approach is supported by the fact that branch position (i.e., lower vs. upper canopy) was not a strong determinant of post-excision reductions in $P_{\mathrm{N}}$ and $g_{\mathrm{s}}$ in sugar maple and tulip poplar; thus, results from preliminary in situ excision tests on lower, more accessible branches and leaves may be assumed to be representative of upper canopy branches. Preliminary tests of the impacts of excision on the shape of $P_{\mathrm{N}}-C_{\mathrm{i}}$ curves could also reveal the extent to which excision related biases affect $g_{s} v s$. photosynthetic capacity. Finally, while not explored directly here, previous work also suggests that preconditioning excised branches in low light and constant temperature for 2-3 d may reduce excisionrelated biases when compared to observation collected in the field shortly after branch cutting (Niinemets et al. 2005). This conditioning approach will not permit observations of gas-exchange rates under in situ stress levels, which are critical for understanding how $P_{\mathrm{N}}$ and $g_{\mathrm{s}}$ vary in response to temporal changes in key environmental drivers. However, the conditioning approach could be appropriate for determining photosynthetic potential and $g_{\mathrm{s}}$ under reference environmental conditions.

\section{References}

Aranda I., Gil L., Pardos J.A.: Water relations and gas exchange in Fagus sylvatica L. and Quercus petraea (Mattuschka) 
Liebl. in a mixed stand at their southern limit of distribution in Europe. - Trees 14: 344-352, 2000.

Beer C., Ciais P., Reichstein M. et al.: Temporal and among-site variability of inherent water use efficiency at the ecosystem level. - Global Biogeochem. Cy. 23: GB2018, 2009.

Bernacchi C.J., Calfapietra C., Davey P.A. et al.: Photosynthesis and stomatal conductance responses of poplars to free-air $\mathrm{CO}_{2}$ enrichment (PopFACE) during the first growth cycle and immediately following coppice. - New Phytol. 159: 609-621, 2003.

Bernacchi C.J., Rosenthal D.M., Pimentel C. et al.: Modeling the temperature dependence of $\mathrm{C}_{3}$ photosynthesis. - In: Laisk A., Nedbal L., Govindjee (ed.): Photosynthesis in silico: Understanding Complexity from Molecules to Ecosystems. Pp. 231-246. Springer, Dordrecht 2009.

Bloomfield K.J., Domingues T.F., Saiz G. et al.: Contrasting photosynthetic characteristics of forest vs. savanna species (Far North Queensland, Australia). - Biogeosciences 11: 7331-7347, 2014.

Brodribb T.J., McAdam S.A., Carins Murphy M.R.: Xylem and stomata, coordinated through time and space: Functional linkages between xylem and stomata. - Plant Cell Environ. 40: 872-880, 2017.

Buckley T.N.: The control of stomata by water balance. - New Phytol. 168: 275-291, 2005.

Campany C.E., Tjoelker M.G., von Caemmerer S., Duursma R.A.: Coupled response of stomatal and mesophyll conductance to light enhances photosynthesis of shade leaves under sunflecks. - Plant Cell Environ. 39: 2762-2773, 2016.

Cano F.J., Sánchez-Gómez D., Rodríguez-Calcerrada J. et al.: Effects of drought on mesophyll conductance and photosynthetic limitations at different tree canopy layers. - Plant Cell Environ. 36: 1961-1980, 2013.

Cochard H., Herbette S., Barigah T. et al.: Does sample length influence the shape of xylem embolism vulnerability curves? A test with the Cavitron spinning technique. - Plant Cell Environ. 33: 1543-1552, 2010.

Dang Q.-L., Margolis H.A., Coyea M.R. et al.: Regulation of branch-level gas exchange of boreal trees: roles of shoot water potential and vapor pressure difference. - Tree Physiol. 17: 521-535, 1997.

Dietze M.C., Vargas R., Richardson A.D. et al.: Characterizing the performance of ecosystem models across time scales: A spectral analysis of the North American Carbon Program site-level synthesis. - J. Geophys. Res.-Biogeo. 116: G04029, 2011.

Domingues T.F., Meir P., Feldpausch T.R. et al.: Co-limitation of photosynthetic capacity by nitrogen and phosphorus in West Africa woodlands. - Plant Cell Environ. 33: 959-980, 2010.

Ellsworth D.S., Liu X.: Photosynthesis and canopy nutrition of four sugar maple forests on acid soils in northern Vermont. Can. J. For. Res. 24: 2118-2127, 1994.

Ethier G.J., Livingston N.J., Harrison D.L. et al.: Low stomatal and internal conductance to $\mathrm{CO}_{2}$ versus Rubisco deactivation as determinants of the photosynthetic decline of ageing evergreen leaves. - Plant Cell Environ. 29: 2168-2184, 2006.

Ewers B., Oren R., Kim H.S. et al: Effects of hydraulic architecture and spatial variation in light on mean stomatal conductance of tree branches and crowns. - Plant Cell Environ. 30: 483-496, 2007.

Flexas J., Ribas-Carbó M., Diaz-Espejo A. et al.: Mesophyll conductance to $\mathrm{CO}_{2}$ : current knowledge and future prospects. - Plant Cell Environ. 31: 602-621, 2008.

Ginn S.E., Seiler J.R., Cazell B.H., Kreh R.E.: Physiological and growth responses of eight-year-old loblolly pine stands to thinning. - For. Sci. 37: 1030-1040, 1991.
Hacke U.G., Sperry J.S.: Functional and ecological xylem anatomy. - Persp. Plant Ecol. Evol. Syst. 4: 97-115, 2001.

Han Q.: Height-related decreases in mesophyll conductance, leaf photosynthesis and compensating adjustments associated with leaf nitrogen concentrations in Pinus densiflora. - Tree Physiol. 31: 976-984, 2011.

Hanson D.T., Green L.E., Pockman W.: Spatio-temporal decoupling of stomatal and mesophyll conductance induced by vein cutting in leaves of Helianthus annuus. - Front. Plant Sci. 4: 365, 2013.

Huxman T.E., Turnipseed A.A., Sparks J.P. et al.: Temperature as a control over ecosystem $\mathrm{CO}_{2}$ fluxes in a high-elevation, subalpine forest. - Oecologia 134: 537-546, 2003.

Joesting H.M., McCarthy B.C., Brown K.J.: Determining the shade tolerance of American chestnut using morphological and physiological leaf parameters. - Forest Ecol. Manag. 257: 280-286, 2009.

Koch G.W., Sillett S.C., Jennings G.M., Davis S.D.: The limits to tree height. - Nature 428: 851-854, 2004.

Kwon H., Choi M.: Generalized hydromechanical model for stomatal responses to hydraulic perturbations. - J. Theor. Biol. 340: 119-130, 2014.

Lange O., Führer G., Gebel J.: Rapid field determination of photosynthetic capacity of cut spruce twigs (Picea abies) at saturating ambient $\mathrm{CO}_{2}$. - Trees 1: 70-77, 1986.

Law B.E., Sun O., Campbell J. et al:: Changes in carbon storage and fluxes in a chronosequence of ponderosa pine. - Glob. Change Biol. 9: 510-524, 2003.

LeBauer D.S., Wang D., Richter K.T. et al.: Facilitating feedbacks between field measurements and ecosystem models. - Ecol. Monogr. 83: 133-154, 2013.

Leuning R., Kelliher F.M., De Pury D.G.G., Schulze E.-D.: Leaf nitrogen, photosynthesis, conductance and transpiration: scaling from leaves to canopies. - Plant Cell Environ. 18: 1183-1200, 1995.

Lichtenthaler H.K., Ač A., Marek M.V. et al.: Differences in pigment composition, photosynthetic rates and chlorophyll fluorescence images of sun and shade leaves of four tree species. - Plant Physiol. Bioch. 45: 577-588, 2007.

Long S.P., Bernacchi C.J.: Gas exchange measurements, what can they tell us about the underlying limitations to photosynthesis? Procedures and sources of error. - J. Exp. Bot. 54: 2393-2401, 2003.

Long S.P., Farage P.K., Garcia R.L.: Measurement of leaf and canopy photosynthetic $\mathrm{CO}_{2}$ exchange in the field. - J. Exp. Bot. 47: 1629-1642, 1996.

Marler T.E., Mickelbart M.V.: Repeated mechanical stress from leaf cuvette influences leaf gas exchange. - HortScience 27: 432-434, 1992.

Martínez-Vilalta J., Poyatos R., Aguadé D. et al.: A new look at water transport regulation in plants. - New Phytol. 204: 105115,2014

Masarovičová E., Štefančík L.: Some ecophysiological features in sun and shade leaves of tall beech trees. - Biol. Plantarum 32: 374-387, 1990.

McAdam S.A., Brodribb T.J.: The evolution of mechanisms driving the stomatal response to vapor pressure deficit. - Plant Physiol. 167: 833-843, 2015.

Meng F.-R., Arp P.A.: Net photosynthesis and stomatal conductance of red spruce twigs before and after twig detachment. - Can. J. For. Res. 23: 716-721, 1992.

Miyazawa Y., Tateishi M., Komatsu H. et al.: Are measurements from excised leaves suitable for modeling diurnal patterns of gas exchange of intact leaves? - Hydrol. Process. 25: 29242930, 2011.

Monson R.K., Trahan N., Rosenstiel T.N. et al.: Isoprene 
emission from terrestrial ecosystems in response to global change: minding the gap between models and observations. Philos. T. Roy. Soc. A 365: 1677-1695, 2007.

Niinemets Ü., Cescatti A., Rodeghiero M., Tosens T.: Leaf internal diffusion conductance limits photosynthesis more strongly in older leaves of Mediterranean evergreen broadleaved species. - Plant Cell Environ. 28: 1552-1566, 2005.

Pan Y., Birdsey R.A., Fang J. et al.: A large and persistent carbon sink in the world's forests. - Science 333: 988-993, 2011.

Pou A., Medrano H., Flexas J., Tyerman S.D.: A putative role for TIP and PIP aquaporins in dynamics of leaf hydraulic and stomatal conductances in grapevine under water stress and rewatering. - Plant Cell Environ. 36: 828-843, 2013.

Roman D.T., Novick K.A., Brzostek E.R. et al.: The role of isohydric and anisohydric species in determining ecosystemscale response to severe drought. - Oecologia 179: 641-654, 2015.

Salleo S., Nardini A., Pitt F., Lo Gullo M.A.: Xylem cavitation and hydraulic control of stomatal conductance in laurel (Laurus nobilis L.). - Plant Cell Environ. 23: 71-79, 2000.

Santiago L.S., Mulkey S.S.: A test of gas exchange measurements on excised canopy branches of ten tropical tree species. Photosynthetica 41: 343-347, 2003.

Schäfer K.V.R., Oren R., Ellsworth D.S. et al:: Exposure to an enriched $\mathrm{CO}_{2}$ atmosphere alters carbon assimilation and allocation in a pine forest ecosystem. - Glob. Change Biol. 9: 1378-1400, 2003.

Schuster W., Monson R.: An examination of the advantages of $\mathrm{C}_{3}-\mathrm{C}_{4}$ intermediate photosynthesis in warm environments. Plant Cell Environ. 13: 903-912, 1990.

Sperry J.S., Wang Y., Wolfe B.T. et al:: Pragmatic hydraulic theory predicts stomatal responses to climatic water deficits. -
New Phytol. 212: 577-589, 2016.

Urban O., Šprtová M., Košvancová M. et al.: Comparison of photosynthetic induction and transient limitations during the induction phase in young and mature leaves from three poplar clones. - Tree Physiol. 28: 1189-1197, 2008.

Valladares F., Allen M.T., Pearcy R.W.: Photosynthetic responses to dynamic light under field conditions in six tropical rainforest shrubs occuring along a light gradient. - Oecologia 111: 505-514, 1997.

Walker A.P., Beckerman A.P., Gu L. et al.: The relationship of leaf photosynthetic traits $-V_{\text {cmax }}$ and $J_{\max }$ - to leaf nitrogen, leaf phosphorus, and specific leaf area: a meta-analysis and modeling study. - Ecol. Evol. 4: 3218-3235, 2014.

Warren C.R.: Why does photosynthesis decrease with needle age in Pinus pinaster? - Trees 20: 157-164, 2006.

Warren C.R., Ethier G.J., Livingston N.J. et al.: Transfer conductance in second growth Douglas-fir (Pseudotsuga menziesii (Mirb.) Franco) canopies. - Plant Cell Environ. 26: 1215-1227, 2003.

Warren J.M., Jensen A.M., Medlyn B.E. et al.: Carbon dioxide stimulation of photosynthesis in Liquidambar styraciflua is not sustained during a 12-year field experiment. - AoB Plants 7: plu074, 2015.

Woodruff D.R., Bond B.J., Meinzer F.C.: Does turgor limit growth in tall trees? - Plant Cell Environ. 27: 229-236, 2004.

Yi K., Dragoni D., Phillips R.P. et al.: Dynamics of stem water uptake among isohydric and anisohydric species experiencing a severe drought. - Tree Physiol. 37: 1379-1392, 2017.

Zhang J., Marshall J.D., Jaquich B.C.: Genetic differentiation in carbon isotope discrimination and gas exchange in Pseudotsuga menziesii: A common garden experiment. Oecologia 93: 80-87, 1993.

(C) The authors. This is an open access article distributed under the terms of the Creative Commons BY-NC-ND Licence. 